\title{
ALTOS E BAIXOS ESTRUTURAIS DO GRUPO SÃO BENTO NA REGIÃO ENTRE RIBEIRÃO PRETO E SERTÃOZINHO, NORDESTE DO ESTADO DE SÃO PAULO
}

\author{
Marcos MASSOLI
}

\begin{abstract}
RESUMO
A região compreendida entre Ribeirão Preto e Sertãozinho, na porção nordeste do estado de São Paulo, apresenta um arcabouço de altos e baixos estruturais, tendo como referência os contatos entre as formações Serra Geral/Botucatu e Botucatu/Piramboia. O primeiro contato (Serra Geral/Botucatu) foi estabelecido a partir de perfis geológicos de poços existentes, enquanto o segundo (Botucatu/Piramboia), nem sempre bem definido por esses perfis, foi também interpretado com base em perfilagens de raios gama de poços, disponíveis principalmente na região de Ribeirão Preto. Os altos e baixos estruturais identificados apresentam direção predominante NE-SW e estariam associados, principalmente, a corpos de diabásio intrudidos na Formação Pirambóia.
\end{abstract}

Palavras-chave: Altos e baixos estruturais; Contato das formações Serra Geral/Botucatu; Contato das formações Botucatu/Piramboia; Perfilagens de raios gama; Mapas de contorno estrutural; Seções geológicas.

\begin{abstract}
STRUCTURAL HIGHS AND LOWS OF THE SÃO BENTO GROUP IN THE REGION BETWEEN RIBEIRÃO PRETO AND SERTÃOZINHO, NORTHEAST OF SÃO PAULO STATE. The region between Ribeirão Preto and Sertãozinho, northeast of São Paulo State, presents a structural framework characterized by structural highs and lows, which were described based on the contacts between the Serra Geral/ Botucatu and Botucatu/Piramboia formations. The first contact (Serra Geral/Botucatu) was determined from geological profiles of wells, and the second one (Botucatu/ Piramboia), which is not always clearly observed in these geological profiles, was also interpreted from gamma-ray well logs, available mainly for the Ribeirão Preto region. The structural highs and lows, mainly NE-SW oriented, are associated with diabase intrusions into the Piramboia Formation.
\end{abstract}

Keywords: Structural highs and lows; Contact between Serra Geral/Botucatu formations; Contact between Botucatu/Piramboia formations; Gamma-ray logs; Structural contour maps; Geological sections.

\section{INTRODUÇÃO}

No estado de São Paulo, SANTORO \& MASSOLI (1985) identificaram irregularidades do topo dos basaltos da Formação Serra Geral, com a caracterização dos baixos estruturais de Santa Fé do Sul, Jales, São José do Rio Preto e Sud Menucci, além dos altos estruturais de Três Fronteiras, Bálsamo, Irapuã, Andradina, Nova Granada e Piratininga. Este último foi formado por falhas de direções NW-SE e NE-SW, que trouxeram à superfície as formações Piramboia e Corumbataí. Posteriormente, PAULA E SILVA (2003) detalhou tais irregularidades do topo da Formação Serra Geral, às quais deu nomes alusivos às cidades onde foram identificadas. SIMONATO et al. (2016), estudando a cidade de Bauru, interpretaram que a área sofreu tectonismo pós-vulcanismo basáltico, anterior à deposição do Grupo Bauru, originando o arcabouço da futura Bacia Bauru. Blocos elevados foram expostos à erosão, com remoção de 
toda a Formação Serra Geral, razão pela qual o Grupo Bauru, na área, sobrepõe-se diretamente à Formação Botucatu. Na porção norte do estado de São Paulo, próximo à divisa com Minas Gerais, ZALAN et al. (1987) apontaram uma estrutura anticlinal, de direção NW-SE, a qual denominaram Alto de Cardoso. Este vai desde a cidade homônima até os arredores de Ribeirão Preto e evidenciaria uma elevação do contato entre o Grupo Bauru e a Formação Serra Geral.

A existência de um baixo estrutural na área urbana de Ribeirão Preto já é conhecida há muito tempo. SINELLI (1971), estudando a tectônica da área, verificou a ocorrência de variações abruptas das cotas do contato entre as formações Serra Geral e Botucatu, interpretando-as como sendo produzidas por falhas. DAVINO \& SINELLI (1973) propõem a existência de uma estrutura do tipo graben nessa região.

Uma seção geológica apresentada por SOARES et al. (1973; figura 3, p. 222) evidencia um afundamento do contato entre as formações Serra Geral e Botucatu entre Ribeirão Preto e Sertãozinho (situada cerca de $15 \mathrm{~km}$ a oeste da primeira), caracterizando um baixo estrutural.

MASSOLI (2007) elaborou diversas seções geológicas a partir da descrição e perfilagens geofísicas de poços da área urbana de Ribeirão Preto pertencentes ao DAERP (Departamento de Água e Esgotos de Ribeirão Preto), as quais revelaram irregularidades nos contatos das unidades geológicas presentes.

Com o auxílio de perfilagens geofísicas, PAULA E SILVA et al. (2008) admitiram a existência de basculamentos no contato entre as formações Serra Geral e Botucatu em Ribeirão Preto, porém atribuíram-nos às irregularidades da paleotopografia das dunas que constituíam o topo da Formação Botucatu, a qual foi recoberta discordantemente pelas lavas basálticas, embora algumas falhas tenham sido constatadas, mas sem influenciar no arcabouço estrutural da área.

FERNANDES et al. (2010; figura 1, pag. 78) apresentaram seção geológica que passa pela área urbana de Ribeirão Preto, na qual está presente um baixo estrutural, que teria sido originado por falhas. Nesse caso, a tectônica teria sido pré-Serra Geral, uma vez que esta unidade geológica não teria sido afetada pelos falhamentos. Esses autores consideraram provável que as irregularidades do contato entre as formações Serra Geral/Botucatu foram causadas pela morfologia pretérita das dunas e não por eventos tectônicos.
Conforme FERNANDES et al. (2011), os basaltos em Ribeirão Preto exibem, além das juntas de resfriamento, fraturas tectônicas sem rejeitos verticais importantes. No estado do Rio Grande do Sul, SCHERER (2000) mostrou que a morfologia das dunas que originaram a Formação Botucatu foi preservada da erosão pelo rápido derramamento de lavas basálticas da Formação Serra Geral, de maneira a configurar uma superfície de contato entre essas duas unidades geológicas bastante ondulada.

Apesar da necessidade de levar a preservação do relevo de dunas em consideração, a literatura mostra que há muitos altos e baixos estruturais nas áreas de ocorrência da Formação Serra Geral. Desta forma, este trabalho tem o objetivo de demonstrar a existência de estruturas desse tipo na região entre as cidades de Ribeirão Preto e Sertãozinho (Figura 1), com base em dados de poços de água subterrânea e perfilagens geofísicas.

\section{MÉTODOS}

Para alcançar os objetivos propostos foram elaborados dois mapas de contorno estrutural, gerados por interpolação manual, que apresentam os contatos das formações Serra Geral/Botucatu e Botucatu/Piramboia, e quatro seções geológicas $(\mathrm{AB}, \mathrm{CD}, \mathrm{EF}$ e $\mathrm{GH}$, Figura 1). A seção $\mathrm{AB}$ corta praticamente toda a área, de Sertãozinho até Ribeirão Preto, na direção aproximada E-W; a seção $\mathrm{CD}$, com direção NE-SW, atravessa praticamente toda a área urbana de Ribeirão Preto; a seção EF, também de direção NE- SW, cruza parte da área urbana de Ribeirão Preto; e a seção GH de direção NW-SE, é aproximadamente perpendicular à direção das camadas geológicas.

$\mathrm{Na}$ área urbana das cidades de Ribeirão Preto e Sertãozinho o número de poços tubulares existentes, respectivamente do DAERP (Departamento de Água e Esgotos de Ribeirão Preto) e do SAEMAS (Serviço Autônomo de Água, Esgoto e Meio Ambiente de Sertãozinho), é bastante significativo, permitindo um traçado mais detalhado das isolinhas dos mapas de contorno estrutural. Já na parte central da área, representativa da zona rural desses dois municípios, as informações de subsuperfície são limitadas; perfis de apenas três poços foram utilizados: um a norte (Cruz das Posses, poço 12 - DAEE), outro no centro (poço 134 - DAEE) e o outro a SW (Dumont). A interpolação das curvas nesta região 
apresenta maiores incertezas. A tabela 1 mostra os poços utilizados no presente estudo.

Perfilagens de raios gama e potencial espontâneo, obtidas junto ao DAERP, também foram interpretadas para comprovação do contato geológico entre as unidades analisadas, conforme procedimento apresentado em MASSOLI (2007) e
PAULA E SILVA et al. (2008). Em geral, o contato entre as formações Serra Geral e Botucatu é facilmente constatado na descrição dos poços cadastrados. Assim mesmo, foram examinadas perfilagens de raios gama e potencial espontâneo de alguns poços para definição de tal contato, que coincide com uma brusca queda no valor da radioatividade

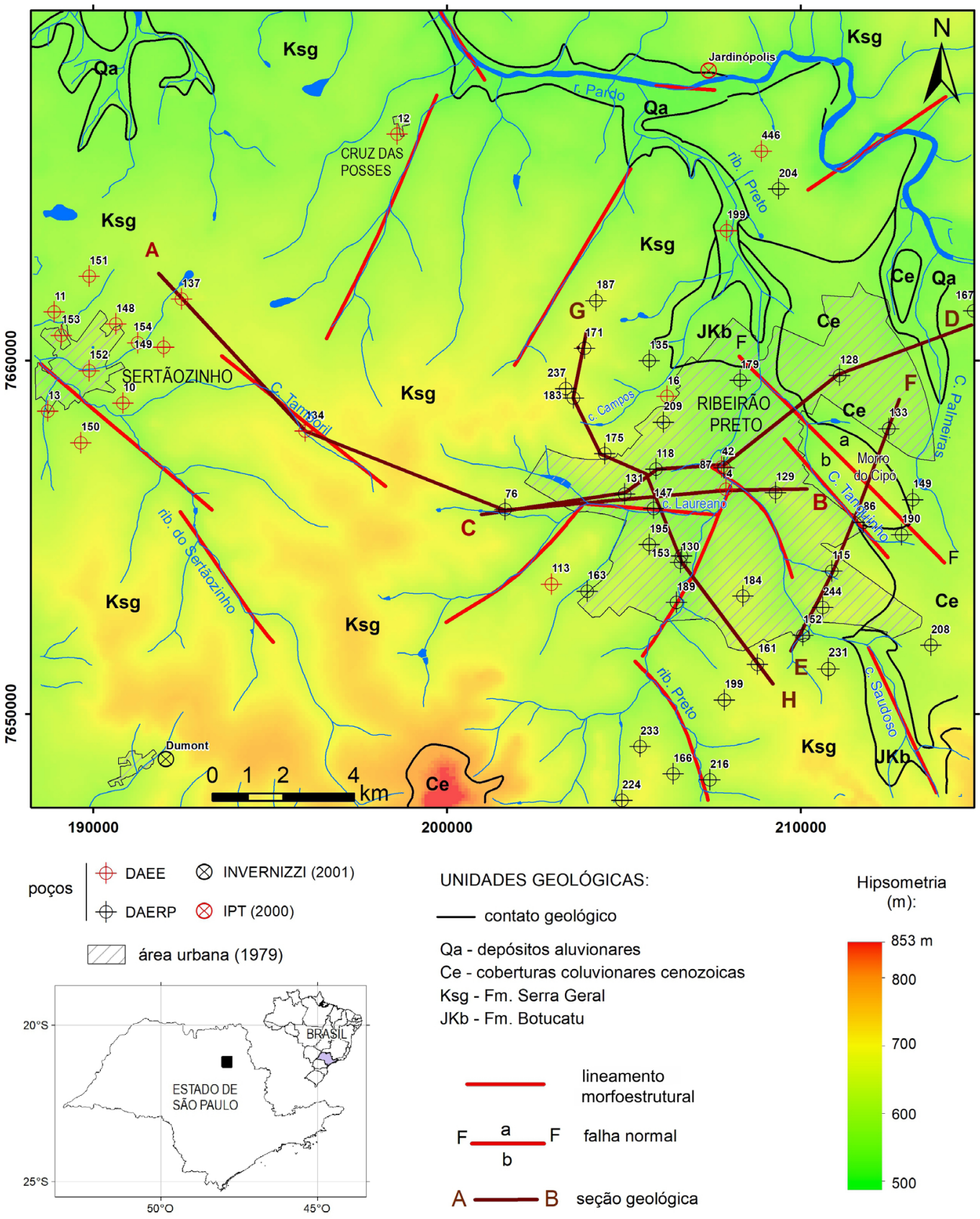

FIGURA 1 - Mapa geológico da área com a localização dos poços e das seções geológicas AB, CD, EF e GH. Fonte: Carta topográfica Ribeirão Preto, escala 1:50.000, IBGE (1979). Hipsometria e modelo digital de terreno gerados a partir do imageamento SRTM/NASA. Coordenadas UTM (WGS 84). 
TABELA 1 - Poços utilizados no presente estudo.

\begin{tabular}{|c|c|c|c|c|c|c|}
\hline Poço & Fonte & $\begin{array}{l}U T M E \\
(\mathrm{~km})\end{array}$ & $\begin{array}{l}U T M N \\
(\mathrm{~km})\end{array}$ & $\begin{array}{l}\text { Cota } \\
\text { do poço } \\
(m)\end{array}$ & $\begin{array}{l}\text { Perfil estratigráfico-profundidade }(\mathrm{m}) \\
\text { (Fm. Serra Geral }=S G, F m . \text { Botucatu }=\text { Bot, Fm. } \\
\text { Piramboia }=\text { Pir, diabásio }=d b, \text { Fm. Corumbatai }=\text { Cor })\end{array}$ & $\begin{array}{l}\text { Perfilagem } \\
\text { geofisica }\end{array}$ \\
\hline 4 & DAEE & 207,90 & 7656,35 & 516 & 0-56 SG; 56-158 Bot; 158-234 Pir; 234-239,50 db & não \\
\hline 10 & DAEE & 190,85 & 7658,79 & 560 & 0-192 SG; 192-402 Bot/Pir; 402-408 db & não \\
\hline 11 & DAEE & 188,90 & 7661,37 & 560 & 0-141 SG; 141-274 Bot; 204-301 Pir; 301-303 db & não \\
\hline 12 & DAEE & 198,60 & 7666,40 & 545 & 0-156 SG; 156-266 Bot; 266-345 Pir & não \\
\hline 13 & DAEE & 188,72 & 7658,56 & 540 & 0-102 SG; 102-198 Bot; 198-337,50 Pir & não \\
\hline 16 & DAEE & 206,23 & 7658,98 & 545 & 0-50 SG; 50-152 Bot; 152-259 Pir & não \\
\hline 42 & DAEE & 207,78 & 7656,98 & 520 & 0-40 SG; 40-147 Bot; 147-222 Pir; 222-224 db & não \\
\hline 113 & DAEE & 202,96 & 7653,67 & 617 & 0-166 SG; 166-256 Bot; 256-277 Pir & não \\
\hline 134 & DAEE & 196,00 & 7658,00 & 615 & 0-234 SG; 234-358 Bot/Pir & não \\
\hline 137 & DAEE & 192,50 & 7661,73 & 600 & 0-109 SG; 109-200 Bot; 200-311 Pir; 311-315 db & não \\
\hline 148 & DAEE & 190,65 & 7661,03 & 570 & 0-120 SG; 120-206-Bot; 206-323 Pir & não \\
\hline 149 & DAEE & 192,00 & 7660,37 & 562 & 0-136 SG; 136-222 Bot; 222-353 Pir & não \\
\hline 150 & DAEE & 189,66 & 7657,67 & 588 & 0 -230 SG; 230-290 Bot; 290-330 Pir; 330-406 db & não \\
\hline 151 & DAEE & 189,89 & 7662,38 & 550 & 0-129 SG; 129-220 Bot; 220-288 Pir; 288-320 db & não \\
\hline 152 & DAEE & 189,89 & 7659,71 & 538 & 0-101 SG; 101-200 Bot & não \\
\hline 153 & DAEE & 189,10 & 7660,71 & 550 & 0-98 SG; 98-200 Bot; 200-254 Pir & não \\
\hline 154 & DAEE & 191,27 & 7660,50 & 555 & 0-100 SG; 100-194 Bot; 194-235 Pir; 235-237 db & não \\
\hline 199 & DAEE & 207,92 & 7663,67 & 500 & 0-3 Aluvião; 3-78 Bot;78-156 Pir & não \\
\hline 446 & DAEE & 208,90 & 7665,92 & 545 & 0-150 SG; $150-230$ Bot & não \\
\hline 76 & DAERP & 201,65 & 7655,78 & 580 & $\begin{array}{l}\text { 0-54 SG; 54-58 Bot; 58-94 db; 94-112 Bot; } 112-123 \mathrm{db} ; 123-142 \text { Bot; } \\
\text { 142-162 db; 162-289, } 30 \text { Pir }\end{array}$ & não \\
\hline 86 & DAERP & 211,78 & 7655,42 & 560 & $0-236 \mathrm{SG}$ & não \\
\hline 87 & DAERP & 207,84 & 7656,96 & 521 & 0-40 SG; 40-222 Bot/Pir; 222-224 db & não \\
\hline 115 & DAERP & 210,89 & 7654,04 & 570 & 0-94 SG; 94-292 Bot/Pir & não \\
\hline 118 & DAERP & 205,92 & 7656,92 & 540 & 0-80 SG; 80-95 Bot; 95-112 db; 112-225 Bot/SG & não \\
\hline 128 & DAERP & 211,11 & 7659,57 & 548 & 0-191,15 Bot/Pir; 191,15-191,30 db & não \\
\hline 129 & DAERP & 209,30 & 7656,26 & 572 & 0-136,50 SG; 136,50-206 Bot; 206-290 Pir; 290-296 db; 296-372,5 Pir & não \\
\hline 130 & DAERP & 206,61 & 7654,28 & 546 & 0-62 SG; 62-183 Bot/Pir & não \\
\hline 131 & DAERP & 205,03 & 7656,22 & 555 & 0-108 SG; 108-302 Bot/Pir; 302-303,5 db & não \\
\hline 133 & DAERP & 212,50 & 7658,07 & 540 & 0-210 Bot/Pir & não \\
\hline 135 & DAERP & 205,73 & 7659,99 & 559 & 0-50 SG; 50-283 Bot/Pir & não \\
\hline 147 & DAERP & 205,85 & 7655,81 & 530 & 0-74 SG; 74-180 Bot; 180-282 Pir; 282-286 db & não \\
\hline 149 & DAERP & 213,18 & 7656,06 & 557 & 0-58 SG; 58-201 Bot/Pir & não \\
\hline 152 & DAERP & 210,07 & 7652,22 & 550 & 0-37 SG; 37-290 Bot/Pir & $\operatorname{sim}$ \\
\hline 153 & DAERP & 206,64 & 7654,47 & 546 & 0-105 SG; $105-320$ Bot/Pir & $\operatorname{sim}$ \\
\hline 161 & DAERP & 208,79 & 7651,40 & 638 & 0-133 SG; 133-248 Bot; 248-392 Pir & $\operatorname{sim}$ \\
\hline 163 & DAERP & 203,97 & 7653,47 & 610 & 0-168 SG; 168-260 Bot; 260-316,70 Pir & não \\
\hline 165 & DAERP & 217,17 & 7660,65 & 544 & 0-249 Bot/Pir; 249-253 db & $\operatorname{sim}$ \\
\hline 166 & DAERP & 206,40 & 7648,30 & 605 & 0-124 SG; $124-160$ Bot; $160-164 \mathrm{db}$ & não \\
\hline 167 & DAERP & 214,90 & 7661,40 & 540 & $\begin{array}{l}\text { 0-50 Bot; 50-90 db; } 90-119 \text { Bot; } 119-131 \mathrm{db} ; 131-186 \text { Pir; } 186-261 \mathrm{db} \\
\text { 261-370 Pir; 370-400 Cor }\end{array}$ & $\operatorname{sim}$ \\
\hline 171 & DAERP & 203,90 & 7660,34 & 638 & 0-168 SG; 168-258 Bot; 258-362 Pir; 362-374 db & não \\
\hline 175 & DAERP & 204,47 & 7657,36 & 635 & 0-173 SG; 173-355 Bot/Pir; 355-360 db & $\operatorname{sim}$ \\
\hline 179 & DAERP & 208,30 & 7659,44 & 525 & 0-30 SG; 30-230 Bot/Pir & não \\
\hline 183 & DAERP & 203,58 & 7658,93 & 640 & 0-146 SG; 146-226 Bot; 226-249 db; 249-362 Pir; 362-367 db & não \\
\hline 184 & DAERP & 208,38 & 7653,33 & 618 & 0-169 SG; 169-376 Bot/Pir & não \\
\hline 187 & DAERP & 204,22 & 7661,69 & 622 & 0-100 SG; 100-166 Bot; 166-300 Pir & não \\
\hline 189 & DAERP & 206,50 & 7653,15 & 533 & 0-78,80 SG; 78,80-301 Bot/Pir & $\operatorname{sim}$ \\
\hline 190 & DAERP & 212,86 & 7655,07 & 565 & 0-130 Bot; 130-236 Pir & $\operatorname{sim}$ \\
\hline 195 & DAERP & 205,73 & 7654,79 & 565 & 0-126 SG; 126-330 Bot/Pir & $\operatorname{sim}$ \\
\hline 199 & DAERP & 207,85 & 7650,39 & 600 & 0-87 SG; 87-201 Bot; 201-313 Pir; 313-315 db & não \\
\hline 204 & DAERP & 209,39 & 7664,85 & 550 & 0-48 SG; 48-142 Bot; 142-241 Pir; 241-242 db & não \\
\hline 208 & DAERP & 213,69 & 7651,94 & 597 & 0-100 Bot; 100-289,20 Pir & não \\
\hline 209 & DAERP & 206,13 & 7658,25 & 600 & 0-110,50 SG; 110,50-303 Bot/Pir & $\operatorname{sim}$ \\
\hline 216 & DAERP & 207,44 & 7848,13 & 587 & 0-86 SG; 86-162 Bot; 162-283 Pir & não \\
\hline 224 & DAERP & 204,96 & 7647,55 & 627 & 0-158 SG; 158-260 Bot; 260-353,50 Pir & não \\
\hline 231 & DAERP & 210,78 & 7651,26 & 606 & 0-24 solo; 24-65 SG; 65-173 Bot; 173-319 Pir; 319-322 db & $\operatorname{sim}$ \\
\hline 233 & DAERP & 205,47 & 7649,07 & 620 & 0-132 SG; 132-186 Bot; 186-220 Pir & não \\
\hline 237 & DAERP & 203,36 & 7659,20 & 656 & 0-175 SG; 175-373 Bot/Pir; 373-375 db & não \\
\hline 244 & DAERP & 210,63 & 7653,01 & 596 & 0-10 solo; 10-90 SG; 90-324 Bot/Pir; 324-329 db & não \\
\hline Dumont & INVERNIZZI (2001) & 192,06 & 7648,72 & 601 & 0-196 SG; 196-204 Bot & não \\
\hline Jardinópolis & IPT (2000) & 207,40 & 7668,20 & 500 & 0-55 SG; 55-100 Bot & não \\
\hline
\end{tabular}


(Figura 2). O contato entre as formações Botucatu e Piramboia já é mais incerto, pois a maioria dos poços consultados não faz referência a tal contato, considerando apenas o conjunto Botucatu + Piramboia indistinto. Diante disso, procurou-se determiná-lo pela análise de perfilagens de raios gama e potencial espontâneo (SP), onde alguns contrastes podem ser observados (Figura 3).

\section{CONTEXTO GEOLÓGICO}

$\mathrm{Na}$ área estudada afloram as seguintes unidades, representadas na coluna cronoestratigráfica da figura 4: Formação Botucatu, Formação Serra Geral, Coberturas Cenozoicas Indiferenciadas e Depósitos Aluvionares Holocênicos.

A unidade geológica mais antiga que ocorre na área é a Formação Botucatu, recoberta pelos basaltos da Formação Serra Geral na porção centro-oeste da área, e por coberturas coluvionares cenozoicas na parte centro-leste, ocorrendo, de modo restrito, nos vales, onde os sedimentos recentes foram erodidos. A unidade compreende predominantemente arenitos finos a médios, bem selecionados, rosados, avermelhados ou esbranquiçados, com espessuras variando entre 80 e $120 \mathrm{~m}$. Eventualmente, pode apresentar intercalações de material argiloso, de espessuras até métricas (MASSOLI 2007, figura 33, pg. 91), indicando a presença de fácies de origem aquática (lacustre), que seria correlacionável à "fácies Santana" (MEZZALIRA et al. 1981). O contato basal desta unidade com a Fm. Piramboia, não aflorante na área, é discordante, sendo marcado por arenito grosso a conglomerático de uma fácies de leques aluviais (MASSOLI 2007, MASSOLI \& CAETANO-CHANG 2007, PAULA E SILVA et al. 2008), imaturo, tendo em vista a presença de matriz feldspática, que lhe confere cor esbranquiçada. Em São Simão (SP) essa fácies conglomerática do topo da Formação Piramboia constitui a fonte das argilas brancas (ball clays) da várzea do ribeirão Tamanduá (PRESSINOTTI 1991), curso d'água que passa cerca de $10 \mathrm{~km} \mathrm{a}$ leste da área em questão, no limite dos municípios de Ribeirão Preto e Serrana. A espessura da Formação Piramboia na área é estimada em torno de $190 \mathrm{~m}$, de maneira que o conjunto das formações Botucatu + Piramboia tem espessura avaliada em pelo menos $280 \mathrm{~m}$, como constatou-se no poço 208 - DAERP, onde a sondagem foi paralisada ainda na Formação Piramboia.

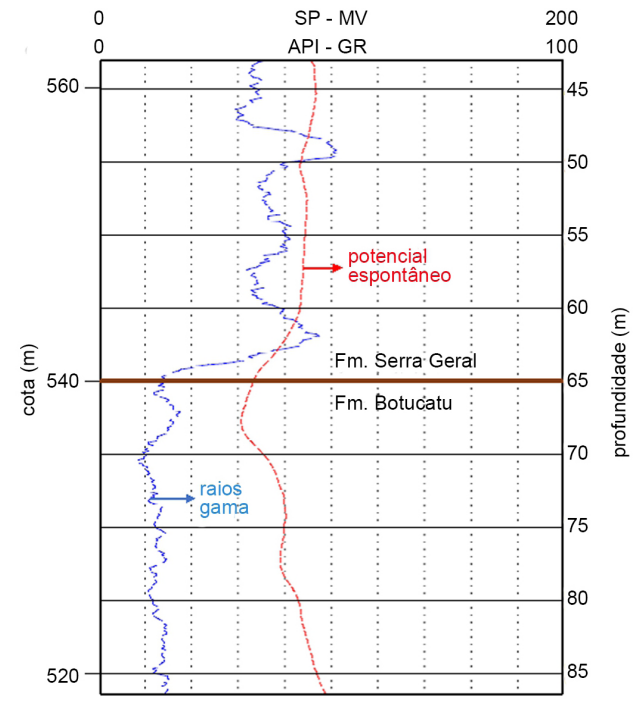

FIGURA 2 - Perfilagem de raios gama e potencial espontâneo: contato entre as formações Serra Geral e Botucatu. Poço 231 - DAERP (localização na figura 1).

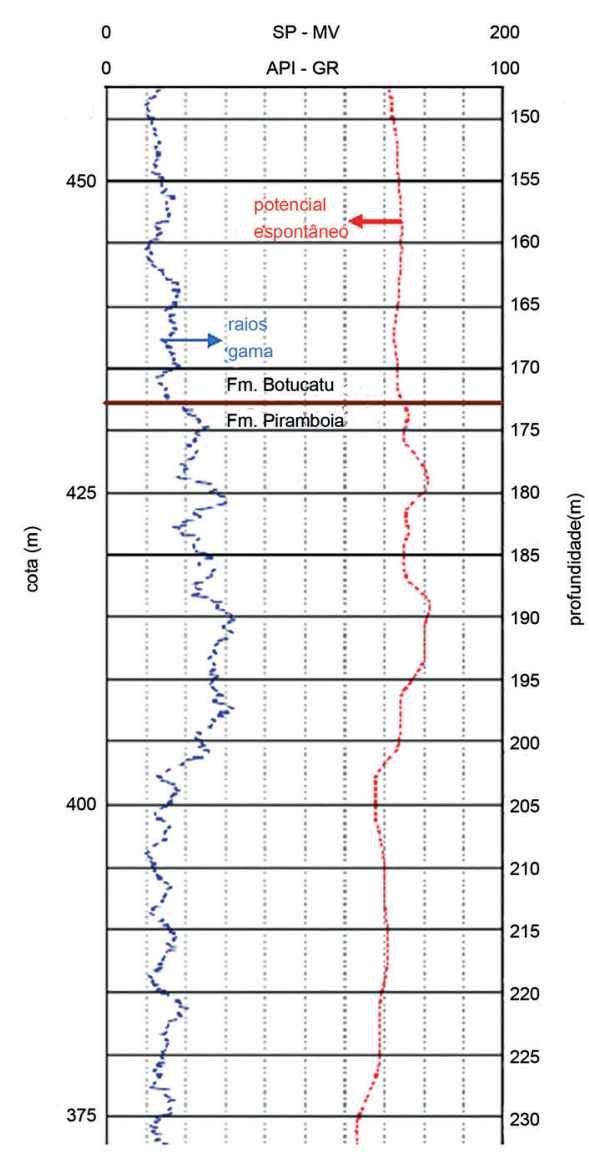

FIGURA 3 - Perfilagem de raios gama e potencial espontâneo: contato entre as formações Botucatu e Piramboia. Poço 231 - DAERP (localização na figura 1). 


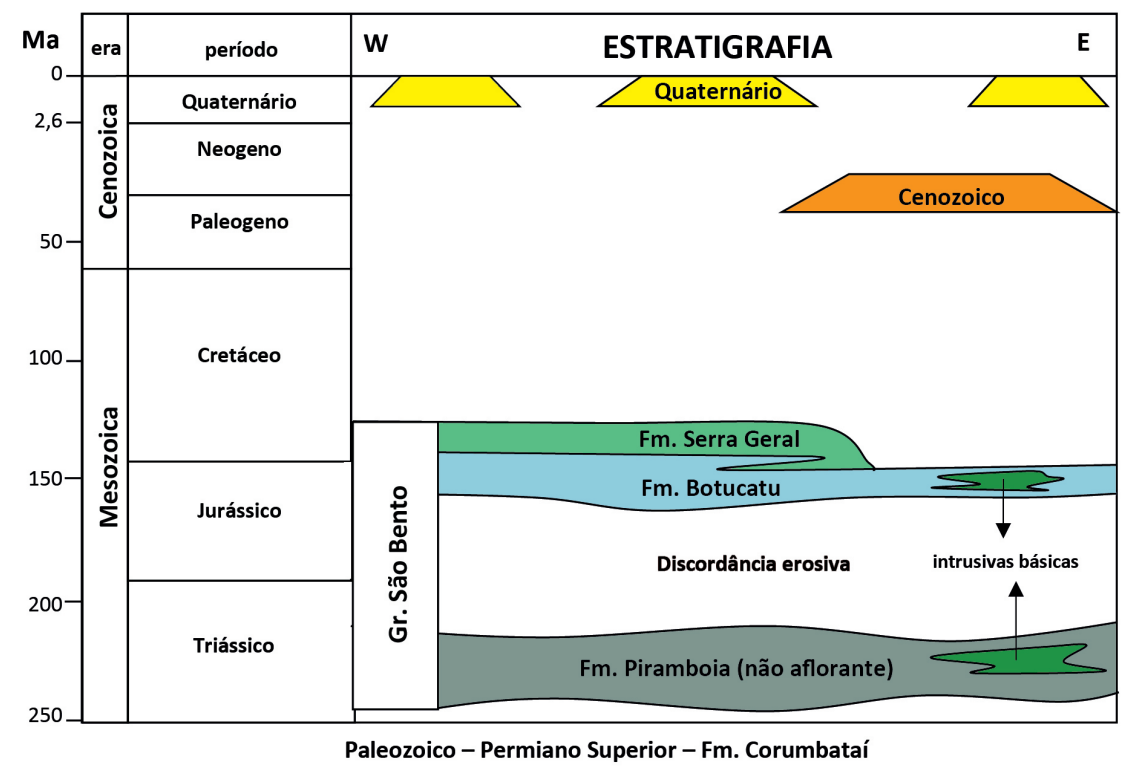

FIGURA 4 - Coluna cronoestratigráfica das unidades geológicas da área de estudo.

A Formação Serra Geral possui espessura que aumenta de leste para oeste, variando de 30 $\mathrm{m}$, junto ao contato com a Formação Botucatu, até cerca de 160 m, a oeste de Ribeirão Preto, em direção à divisa com o município de Sertãozinho; tais espessuras são, no entanto, aparentes, uma vez que já foi parcialmente erodida. Intrusivas básicas, associadas à Formação Serra Geral, não afloram na área estudada; elas foram identificadas apenas em subsuperfície, com base nos perfis geológicos dos poços tubulares, principalmente em cotas inferiores a $300 \mathrm{~m}$, altitude essa que diminui para oeste, em direção ao centro da cidade. Uma intrusão na Formação Piramboia, na porção nordeste da área de estudo, possui $70 \mathrm{~m}$ de espessura. $\mathrm{O}$ contato basal da Formação Serra Geral com a Formação Botucatu é nítido nas perfilagens de raios gama, cuja curva mostra uma inflexão abrupta, com os valores da radioatividade decrescendo de cerca de 50 API para até 10 API (Figura 2). O valor de 10 API indica a presença de arenitos limpos, sem matriz; a curva de SP também tem o mesmo comportamento, apresentando uma inflexão para a esquerda, em direção aos valores mais baixos do potencial espontâneo, caindo de 90 MV para 60 MV. Já o contato entre as formações Botucatu e Piramboia mostra aumento dos valores de radioatividade e SP (Figura 3), conforme apresentado por MASSOLI (2007), MASSOLI \& CAETANO-CHANG (2007) e PAULA E SILVA et al. (2008). Entre as profundidades de $173 \mathrm{~m}$ e $203 \mathrm{~m}$, verifica-se que a linha de raios gama passa de 10 API para 30 API. Esta elevação sugere a presença de cimento caulínico, característica típica da Formação Piramboia. Abaixo dos $203 \mathrm{~m}$ a radioatividade cai novamente para cerca de 10 API. O mesmo acontece com a curva de potencial espontâneo, com os valores de SP subindo de $140 \mathrm{MV}$ para $160 \mathrm{MV}$.

A porção centro-leste da área de estudo contem depósitos coluvionares, areno-argilosos ou, localmente, argilo-arenosos, com espessuras variando desde poucos metros, nos vales, até cerca de $25 \mathrm{~m}$, nos espigões. Tais coberturas neocenozoicas, que recobrem principalmente a Formação Botucatu, são resultantes do retrabalhamento, por gravidade ou correntes superficiais, dos produtos de alteração de basaltos e arenitos. Ocorrem em áreas de topografia suave, relevo colinoso, raramente ultrapassando a cota de $620 \mathrm{~m}$. No entanto, na porção sul da área (coordenadas UTM 7648 km N e UTM 200 km O), a leste de Dumont, ocorre sobre os basaltos um capeamento arenoso, castanho-claro, na cota de cerca de $780 \mathrm{~m}$, posicionado no divisor de águas das bacias hidrográficas dos rios Pardo e Mogi Guaçu, que se diferencia do Latossolo Roxo encontrado nos arredores, proveniente do intemperismo dos basaltos. Tal ocorrência evidencia a presença de uma superfície de erosão mais antiga, quando comparada às coberturas recentes das cotas de cerca de $620 \mathrm{~m}$, no vale do rio Pardo.

Depósitos aluvionares, de idade holocênica, ocorrem nas planícies de inundação do rio Pardo e de seus principais afluentes, como o ribeirão Preto 
e córrego das Palmeiras. Os depósitos do rio Pardo chegam a atingir espessuras de até $8 \mathrm{~m}$, constituídos por areias, argilas e cascalhos.

\section{MAPAS DE CONTORNO ESTRUTURAL E SEÇÕES GEOLÓGICAS}

O mapa de contorno estrutural do contato entre as formações Serra Geral e Botucatu evidencia a existência de altos e baixos estruturais (Figura 5).

Na parte central da cidade de Ribeirão Preto configura-se a presença de uma depressão alongada na direção NE-SW, com decréscimo das cotas do contato entre as formações Serra Geral e Botucatu. Situação similar ocorre no setor nordeste da área, onde esse mesmo contato mostra cotas mais baixas, em torno de 395 m (poço 446 - DAEE, figura 1), com a rocha basáltica apresentando espessura de $150 \mathrm{~m}$.

No setor oeste da área urbana de Ribeirão Preto configura-se um alto estrutural de direção NE-SW, onde o contato entre as formações Serra Geral e Botucatu situa-se à cota de $525 \mathrm{~m}$ (Figura 5). Nesse caso, com a rocha basáltica apresentando menor espessura.

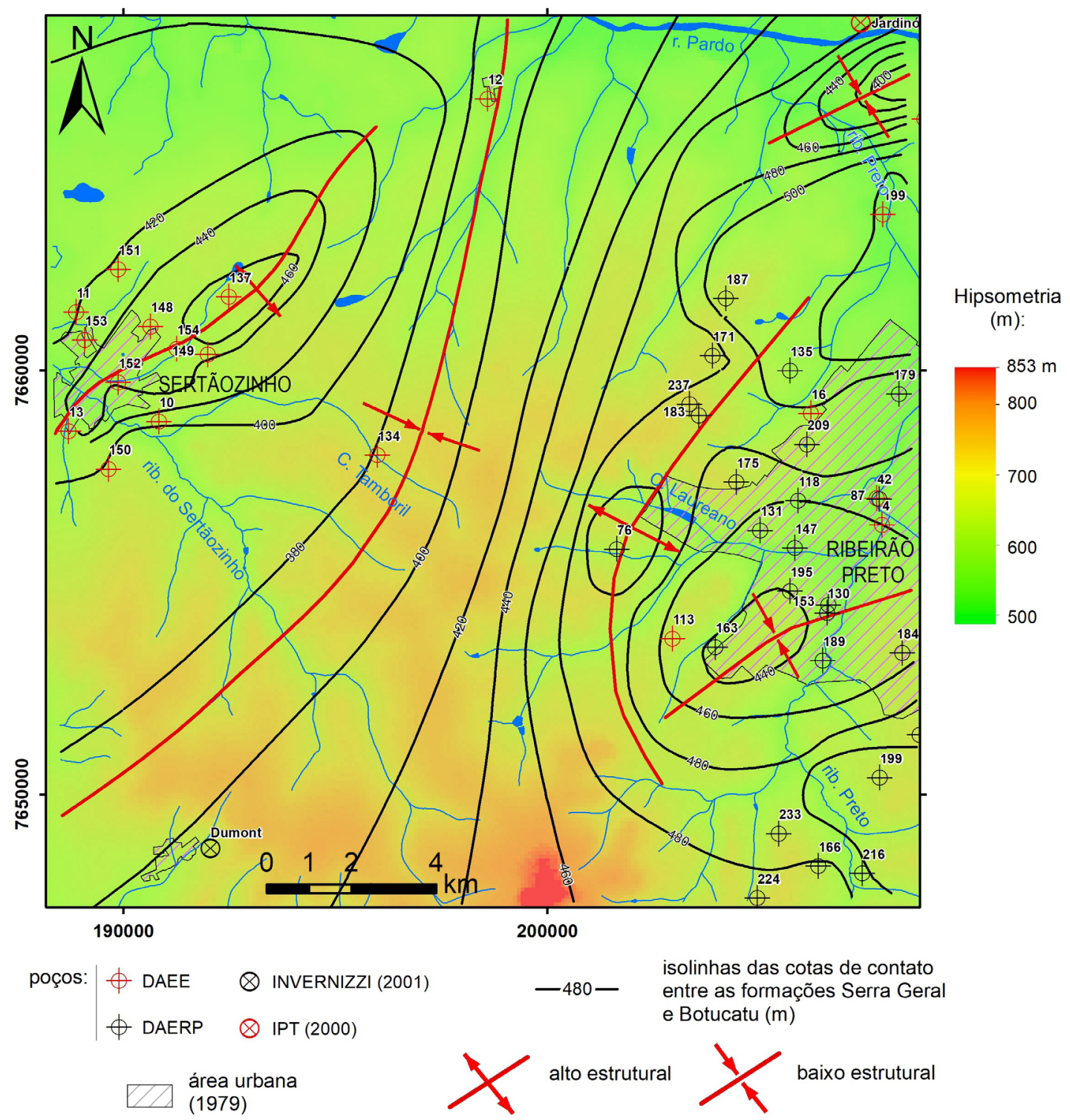

FIGURA 5 - Mapa de contorno estrutural do contato entre as formações Serra Geral e Botucatu. Nas regiões de baixa densidade de poços, o traçado das isolinhas envolve muita incerteza. Base topográfica do IBGE (1979). Hipsometria e modelo digital de terreno gerados a partir do imageamento SRTM/NASA. Coordenadas UTM (WGS 84). 
$\mathrm{Na}$ porção central da área, entre as cidades de Ribeirão Preto e Sertãozinho, apesar da deficiência de dados, existe um indicativo de um baixo estrutural, com eixo de direção NE-SW, na cota aproximada de $390 \mathrm{~m}$, desde o norte da cidade de Dumont, a sudoeste, até o distrito de Cruz das Posses, a nordeste (Figura 5).

$\mathrm{Na}$ área urbana de Sertãozinho, o contato entre as formações Serra Geral e Botucatu eleva-se de cerca de 400 até $475 \mathrm{~m}$, caracterizando um alto estrutural com eixo na direção NE-SW (Figura 5).
O mapa de contorno estrutural do contato entre as formações Botucatu e Piramboia (Figura 6) também evidencia altos e baixos estruturais com distribuição similar ao do mapa de contato entre as formações Serra Geral e Botucatu (Figura 5). Os mesmos elementos estruturais são apresentados de forma sintética na figura 7. Tal configuração também é evidenciada na seção geológica $\mathrm{AB}$ (Figura 8), entre os poços 76 - DAERP e 134 - DAEE, onde o topo da Formação Botucatu apresenta um mergulho de $20 \mathrm{~m} / \mathrm{km}$ para oeste, da cota $470 \mathrm{~m}$

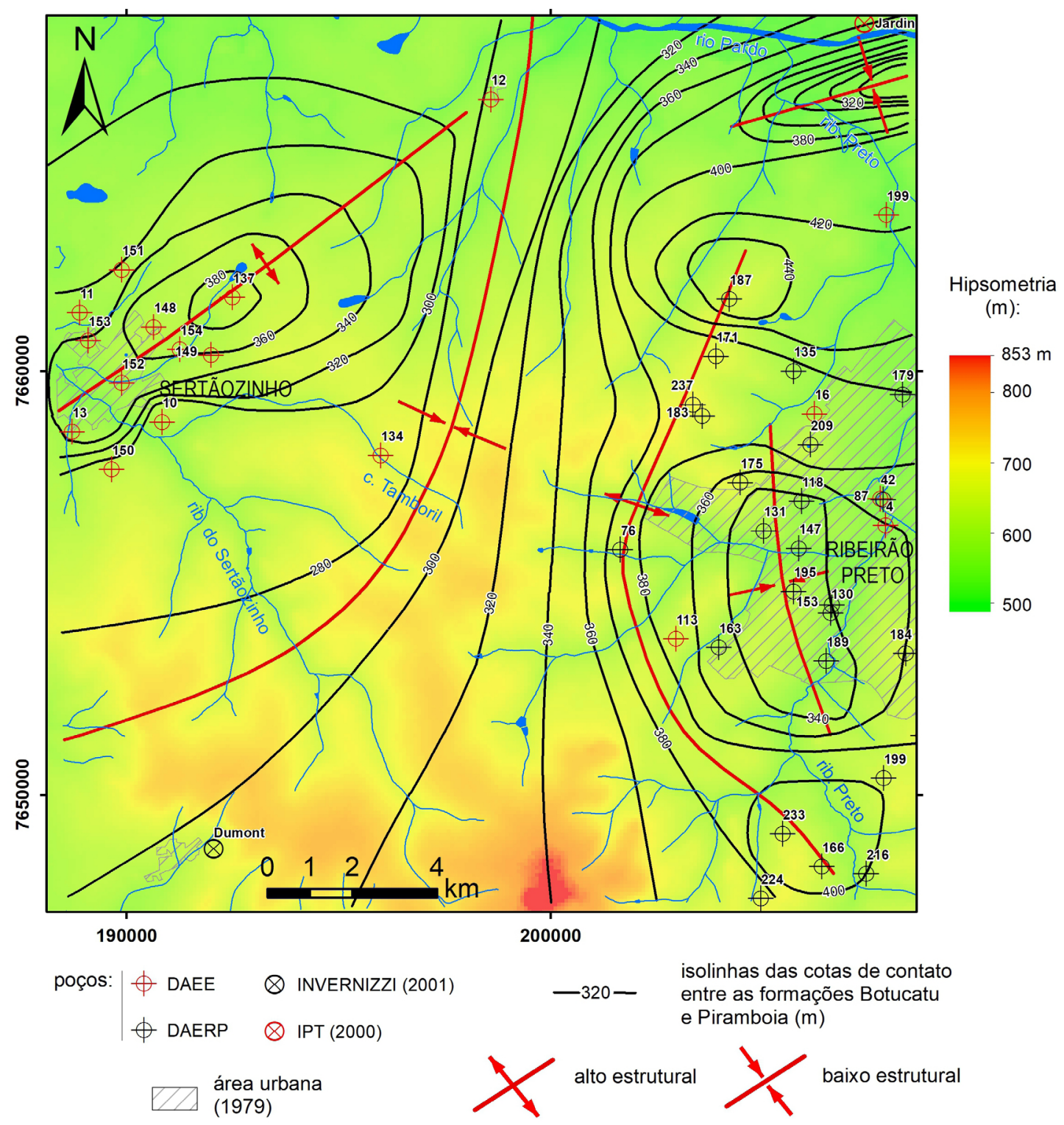

FIGURA 6 - Mapa de contorno estrutural do contato entre as formações Botucatu e Piramboia. Nas regiões de baixa densidade de poços, o traçado das isolinhas envolve muita incerteza. Base topográfica do IBGE (1979). Hipsometria e modelo digital de terreno gerados a partir do imageamento SRTM/NASA. Coordenadas UTM (WGS 84). 


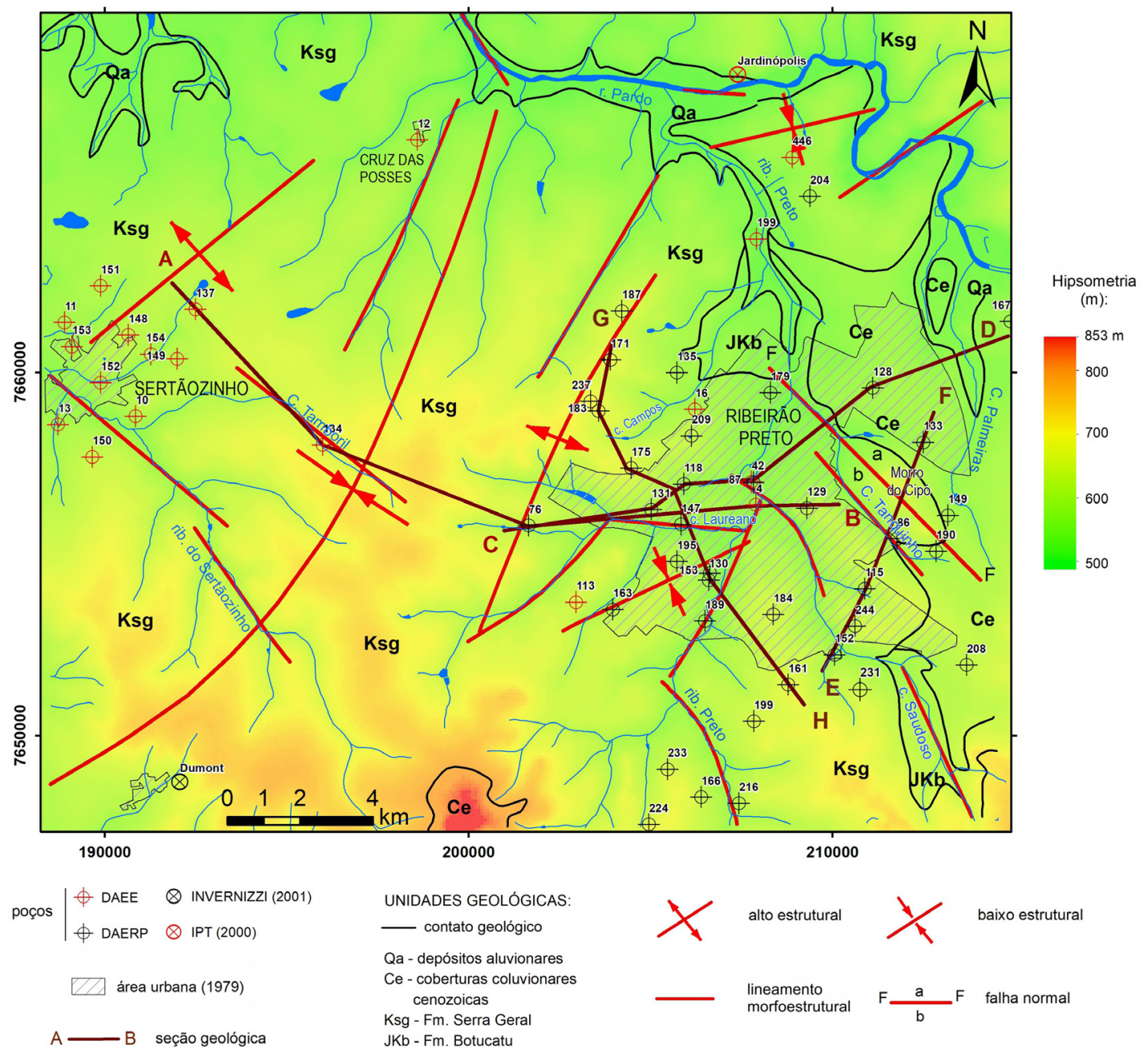

FIGURA 7 - Mapa síntese dos elementos estruturais sobre o mapa geológico. Mapa topográfico do IBGE (1979). Hipsometria e modelo digital de terreno gerados a partir do imageamento SRTM/NASA. Coordenadas UTM (WGS 84).

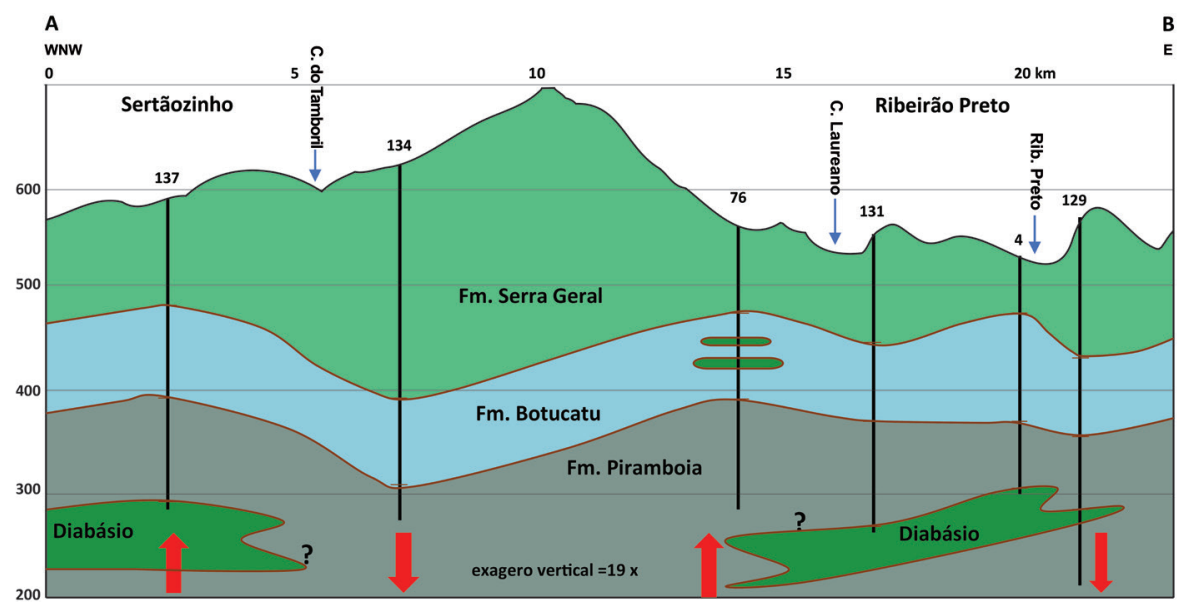

FIGURA 8 - Seção geológica AB entre Sertãozinho e Ribeirão Preto (Localização da seção na figura 7). Setas vermelhas indicam altos $(\uparrow)$ e baixos $(\downarrow)$ estruturais. 
para $380 \mathrm{~m}$, para, em seguida, atingir $490 \mathrm{~m}$, em Sertãozinho; o mesmo ocorre com o topo da Formação Piramboia.

Uma possível hipótese para explicar esse comportamento estrutural dos contatos entre as formações Serra Geral/Botucatu e Botucatu/ Piramboia seria a presença de intrusões de diabásio na Formação Piramboia, de espessuras significativas e a grandes profundidades, que teriam arqueado as camadas, originando altos estruturais (Figura 7). Na área urbana de Sertãozinho o poço 150 - DAEE atingiu um corpo de diabásio na cota de $260 \mathrm{~m}$ (a $330 \mathrm{~m}$ de profundidade), com pelo menos $76 \mathrm{~m}$ de espessura, intrusivo na Formação Piramboia (Figuras 5, 6 e 9a). Considera-se que essa intrusão foi atingida pelo poço 137 - DAEE, na cota de $290 \mathrm{~m}$ (Figura 8); corresponderia a um corpo de forma lacolítica, arqueando as rochas encaixantes e formando um alto estrutural (Figuras $5,6,7)$. Essa concepção da existência de corpos intrusivos de forma lacolítica na área já foi anteriormente apresentada por SINELLI et al. (1984).

Por outro lado, na área urbana de Ribeirão Preto diversos poços atingiram corpos de diabásio em cotas inferiores a $300 \mathrm{~m}$, porém sem atravessá-los totalmente, perfurando-os não mais que $5 \mathrm{~m}$, de maneira que não é possível estabelecer as espessuras reais de tais intrusões, ou mesmo, averiguar se seria apenas uma única intrusão.

No entanto, sondagem realizada na zona nordeste de Ribeirão Preto (poço 167 - DAERP), (a)

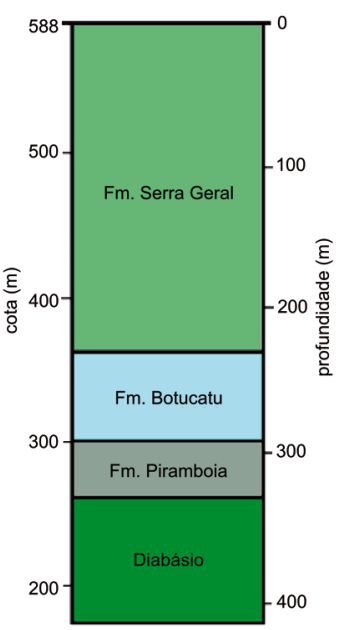

(b)

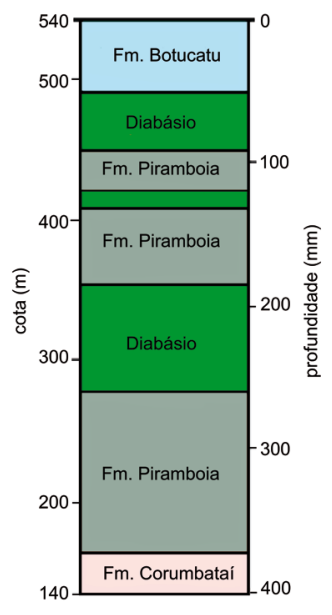

FIGURA 9 - (a) Perfil geológico do poço 150 - DAEE em Sertãozinho; (b) Perfil geológico do Poço 167 DAERP de Ribeirão Preto. atingiu o contato inferior da Formação Piramboia com a Formação Corumbataí (Figuras 9b e 10). Esse furo atravessou uma soleira de diabásio, com espessura de $75 \mathrm{~m}$, a partir da cota de $354 \mathrm{~m}$, intrusivo na parte média da Formação Piramboia. Detectou-se no mesmo poço duas outras soleiras de diabásio, a mais rasa com espessura de $40 \mathrm{~m}$, alojada no contato entre as formações Botucatu e Piramboia, e a outra, com $10 \mathrm{~m}$, encaixada no topo da Formação Piramboia (Figuras 9b e 10). Esses corpos intrusivos de diabásio, no entanto, não apresentam continuidade lateral para oeste-sudoeste, em direção à região central de Ribeirão Preto. Por outro lado, a intrusão superior, situada no contato entre as formações Botucatu e Piramboia (Figura 10), apresenta continuidade para leste, conforme já observado por SOARES et al. (1973), adentrando o município de Serrana, constituindo o que se denominou aqui, informalmente, Soleira de Serrana. Esta se prolonga para Santa Cruz da Esperança e Cajuru, marcando o contato entre as formações Botucatu e Piramboia. A seção CD (Figura 10) mostra que as unidades geológicas mergulham uniformemente para oeste, em direção ao baixo estrutural existente identificado no poço 131 - DAERP; porém, nesse caso, a intrusão é tabular e concordante, formando uma soleira.

A descontinuidade lateral de intrusões básicas na Formação Botucatu também é evidenciada pelo poço 76 - DAERP (Figura 10), situado na parte central da área, onde duas intrusões, a mais rasa com espessura de $11 \mathrm{~m}$ e a mais profunda com $20 \mathrm{~m}$, não foram detectadas pelo poço 131 - DAERP, localizado a leste. Situação semelhante ocorre com o corpo básico cortado pelo poço 118 - DAERP, com 17 m de espessura, que não ocorre nos poços adjacentes (131 e 87, Figura 10).

$\mathrm{Na}$ área do morro do Cipó, situado cerca de $2.500 \mathrm{~m}$ a sul do Aeroporto de Ribeirão Preto, ocorre uma intrusão de diabásio de forma ovalada, na forma de um lacólito, associada a uma falha preenchida por diabásio, razão pela qual as espessuras da rocha básica são muito elevadas nessa área (Figura 11). O poço 86 - DAERP perfurou $144 \mathrm{~m}$ de rocha básica; em direção aos poços 115 , 244 e 152 as cotas do contato entre as formações Serra Geral e Botucatu tornam-se gradativamente mais altas. A falha acima referida já havia sido constatada por PAULA E SILVA et al. (2008), em função do deslocamento do contato entre as formações Botucatu e Piramboia. Nota-se, o basculamento do contato, com rejeito da ordem de $70 \mathrm{~m}$, 


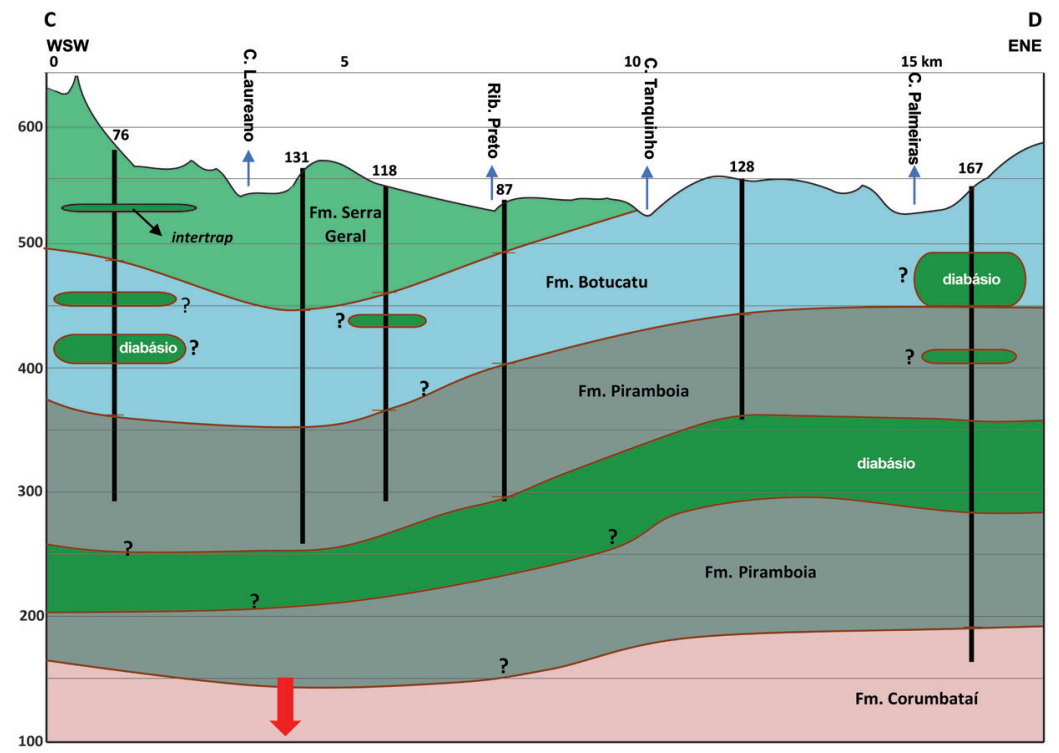

FIGURA 10 - Seção geológica CD (Localização da seção na figura 7). Seta vermelha indica baixo ( $\downarrow$ ) estrutural.

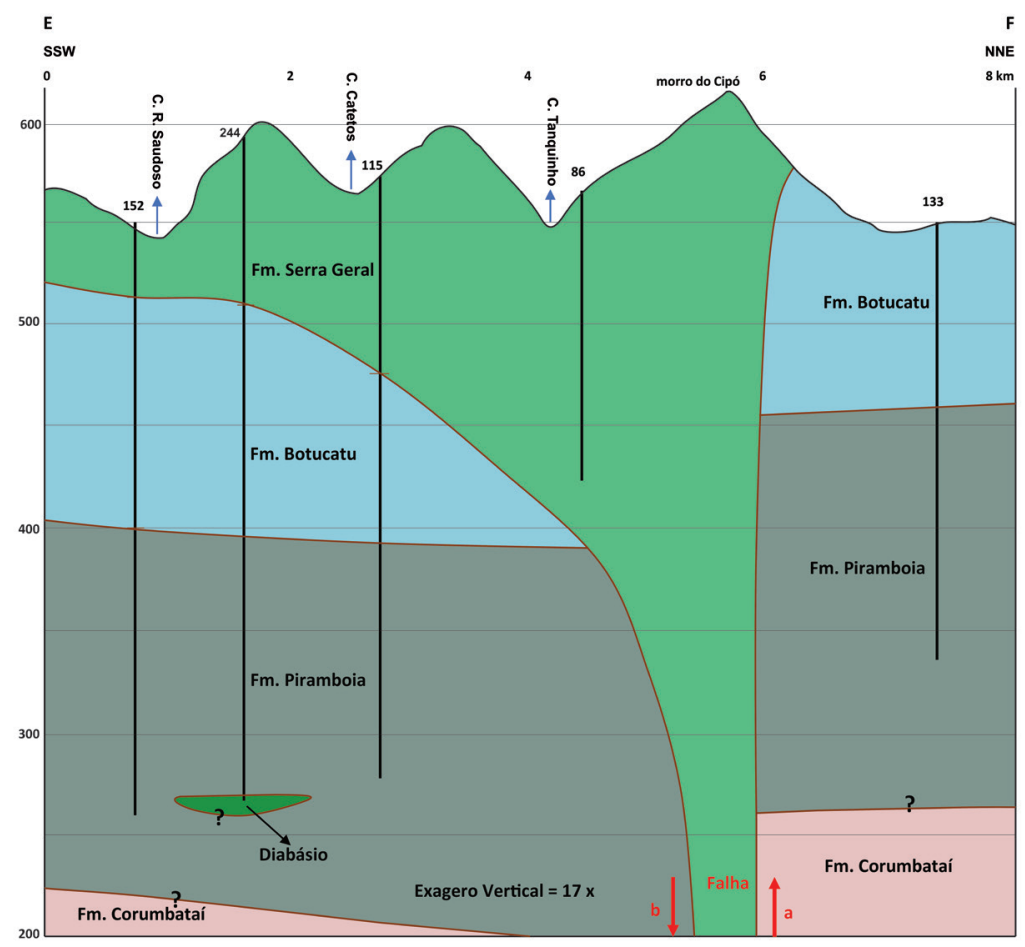

FIGURA 11 - Seção geológica EF, representando o corpo intrusivo associado à zona de falha. Localização da seção geológica na figura 7 .

entre as formações Botucatu e Piramboia, evidenciado pela diferença de cotas entre o poço 133 (470 m) e os poços 152, 244 e 115 (400 m), localizados do outro lado da intrusão.

Esta feição foi identificada em estudos anteriores de sondagem elétrica vertical (USP Ribeirão Preto, informação verbal), que resultaram em um mapa de isópacas da rocha básica, cuja forma alongada apresentava espessuras decrescentes do centro para as bordas, desde mais de $300 \mathrm{~m}$ até $100 \mathrm{~m}$. Essa feição, também assinalada no trabalho realizado por PAULA E SILVA et al. (2008), indica, portanto, um núcleo de injeção magmática. De fato, um poço perfurado no alto da encosta do 
morro do Cipó, na cota de 600 m, atingiu a profundidade de $240 \mathrm{~m}$ sem sair da rocha básica, ao passo que outro, o Jardim Palmares II (DAERP 149, Figura 7), situado cerca de $600 \mathrm{~m}$ a nordeste, na cota de $560 \mathrm{~m}$, cortou $58 \mathrm{~m}$ de diabásio e atingiu a Formação Botucatu.

Ressalta-se que o contato entre as formações Piramboia e Corumbataí não é conhecido nessa área, porém admite-se uma espessura de $190 \mathrm{~m}$ para a Formação Piramboia, obtida no poço 167 DAERP (Figura 9b). Este foi o único na região que atingiu a Formação Corumbataí, sendo possível demarcar o topo e a base da Formação Piramboia. Na seção EF (Figura 11), o contato entre as formações Piramboia e Corumbataí foi inferido com base na informação desse poço.

A seção geológica GH (Figura 12), com direção aproximada NW-SE (Figura 7), foi construída com base em perfis geológicos de poços do DAERP, nos quais foram realizadas perfilagens de raios gama disponíveis em PAULA E SILVA et al. (2008). A seção mostra um baixo estrutural na altura do córrego Laureano, região central da cidade de Ribeirão Preto, e um alto estrutural para NW, possivelmente causado por uma intrusão básica descontínua, já que os poços 171, 183 e 175 atingiram diabásio na porção intermediária da Formação Piramboia, o que não ocorre nos poços 118, 153 e 161 . O contato entre as formações Piramboia e Corumbataí não é conhecido, mas foi inferido novamente com base no poço 167 - DAERP.

Tomando-se o contato entre as formações Botucatu e Piramboia, determinado a partir de três poços do DAERP $(238,109$ e 169) com perfilagens de raios gama (MASSOLI 2008), verificou-se que as camadas mergulham em geral para oeste-noroeste (direção N4E, mergulho de 1'30' para NW), seguindo o padrão geral desde a borda da bacia. $\mathrm{Na}$ área de estudo, em função da existência de altos e baixos estruturais, os mergulhos têm sentidos variáveis, até opostos.

Falhas ocorreriam apenas localmente, como constatado em PAULA E SILVA et al. (2008). Considera-se que, de um modo geral, os desnivelamentos dos contatos entre as formações Serra Geral/Botucatu e Botucatu/Piramboia estariam relacionado a intrusões de formas lacolíticas de rocha básica e apófises relacionadas. Tais intrusões ocorrem principalmente na parte inferior da Formação Piramboia, atingindo espessuras de pelo menos $75 \mathrm{~m}$; intrusões em cotas mais elevadas,

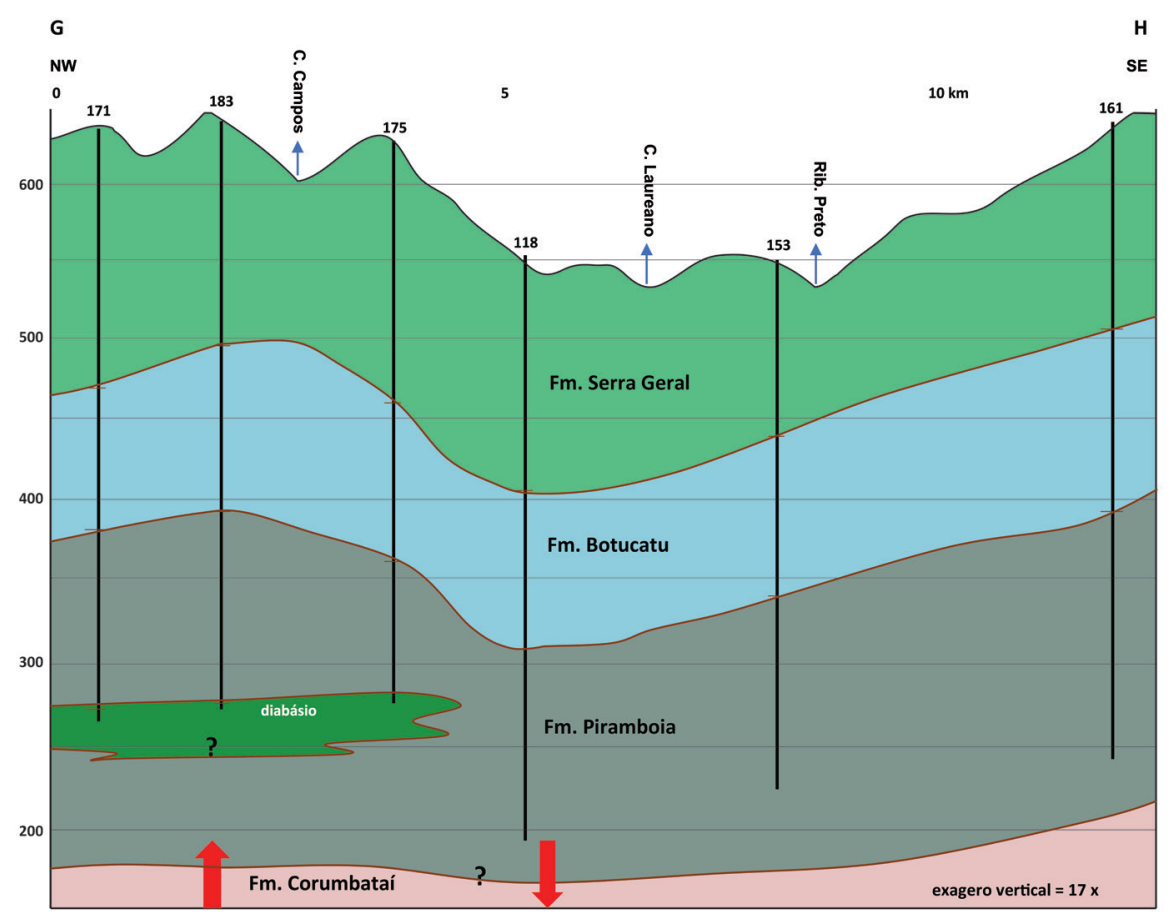

FIGURA 12 - Seção geológica seguindo o mergulho das camadas (ver localização na figura 7). Setas vermelhas indicam altos $(\uparrow)$ e baixos $(\downarrow)$ estruturais. Poços perfilados por PAULA E SILVA (2003): 1089 (DAERP 171), 1246 (DAERP 183), 1248 (DAERP 175), 1028 (DAERP 118), 1009 (DAERP 153) e 1253 (DAERP 161). 
dentro da Formação Botucatu, revelaram-se descontínuas e pouco espessas.

O desnivelamento do contato entre as formações Serra Geral/Botucatu poderia ser explicado em função das irregularidades do relevo pretérito da Formação Botucatu, porém o mesmo comportamento é observado no contato entre as formações Botucatu/Piramboia, mostrando um paralelismo entre as unidades do Grupo São Bento. Levandose em conta a discordância existente entre as formações Botucatu e Piramboia, provavelmente do Triássico Médio ao início do Jurássico Superior, a superfície do Piramboia não seria irregular, mas teria sido aplainada pelos efeitos da erosão no longo período em que ficou exposta, antes do início da deposição da Formação Botucatu (MASSOLI \& CAETANO-CHANG 2007).

A presença de intrusões de rocha básica, notadamente na Formação Piramboia, constitui-se numa barreira ao fluxo das águas subterrâneas, além de interferir no cálculo das reservas do Sistema Aquífero Guarani (SAG). Por exemplo, o poço 167 , hoje desativado, com $400 \mathrm{~m}$ de profundidade e tendo atravessado três intrusões de diabásio, totalizando $127 \mathrm{~m}(40+12+75 \mathrm{~m})$ forneceu baixa produtividade, em torno de $91 \mathrm{~m}^{3} / \mathrm{h}$, enquanto, em geral, um poço que explora o Aquífero Guarani na área, sem a interferência das rochas intrusivas, produz até $300 \mathrm{~m}^{3} / \mathrm{h}$, principalmente na porção confinada (DAEE/IG/IPT/CPRM 2005).

\section{CONCLUSÕES}

$\mathrm{Na}$ área compreendida entre Ribeirão Preto e Sertãozinho foram identificados altos e baixos estruturais com direção predominante NE-SW. Os mapas de contorno dos contatos entre as formações Botucatu/Piramboia e Serra Geral/Botucatu mostram uma mesma configuração estrutural.

Considera-se que os desnivelamentos dos contatos entre as unidades do Grupo São Bento na porção centro-oeste da área podem estar associados a intrusões de corpos básicos de espessuras irregulares, com formas lacolíticas, alojados na porção intermediária da Formação Piramboia. Tais corpos teriam provocado o arqueamento das camadas sedimentares, sem, contudo, deslocá-las. Por outro lado, na porção leste da área, onde os contatos entre as unidades geológicas encontram-se aproximadamente paralelos, a intrusão profunda de diabásio na parte intermediária da Formação Piramboia é de forma tabular, representando uma soleira. Além disso, na área urbana de Ribeirão
Preto, constatou-se uma intrusão de diabásio na forma de um lacólito, associada a uma falha normal de direção NW-SE com rejeito vertical em torno de 70 $\mathrm{m}$, que constitui o topo de uma elevação topográfica alongada, denominada localmente de morro do Cipó.

Já as intrusões de diabásio alojadas na Formação Botucatu revelaram-se descontínuas e pouco espessas.

O desnivelamento do contato entre as formações Serra Geral e Botucatu poderia ser explicado por irregularidades da superfície de dunas, contemporânea aos derrames da Formação Serra Geral. No entanto, o mesmo não se pode dizer com relação ao topo da Formação Piramboia, já que a superfície desta unidade foi aplainada pela erosão, pelo menos entre o Triássico Médio e o Jurássico Superior, originando a discordância existente entre as formações Piramboia e Botucatu.

As intrusões de rocha básica tem relevância hidrogeológica, pois constituem barreiras ao fluxo das águas subterrâneas do Sistema Aquífero Guarani (SAG) e podem reduzir a produtividade dos poços.

\section{AGRADECIMENTOS}

Aos relatores e editores da Revista do Instituto Geológico pelas sugestões apresentadas que enriqueceram o trabalho e pelo auxílio na confecção das ilustrações. Ao DAERP e DAEE, por permitirem a consulta aos seus cadastros de poços tubulares.

\section{REFERÊNCIAS BIBLIOGRÁFICAS}

\section{DAEE/IG/IPT/CPRM - DEPARTAMENTO} DE ÁGUAS E ENERGIA ELÉTRICA / INSTITUTO GEOLÓGICO / INSTITUTO DE PESQUISAS TECNOLÓGICAS DO ESTADO DE SÃO PAULO / SERVIÇO GEOLÓGICO DO BRASIL. 2005. Mapa de águas subterrâneas do Estado de São Paulo: escala 1:1.000.000. São Paulo, coordenação geral: Gerôncio Rocha, Nota explicativa, 119 p. e 2 anexos (mapa e CD-ROM).

DAVINO, A.; SINELLI, 0. 1973. Métodos geofísicos aplicáveis às províncias hidrogeológicas do Estado de São Paulo. In: SBG, CONGRESSO BRASILEIRO DE GEOLOGIA, 27, Aracaju, Anais, 1: 347351. 
FERNANDES, A.J.; MAIDANER, C.H.; AZEVEDO SOBRINHO, J.M.; PRESSINOTTI, M.M.N.; WAHNFRIED, I. 2010. Estratigrafia dos derrames de basaltos da Formação Serra Geral (Ribeirão Preto - SP) baseada na geologia física, petrografia e geoquímica. Geologia USP, Série Cientifica, 10(2): 73-99.

FERNANDES， A.J.; MALDANER， C.H.; ROULEAU, A. 2011. Análise de fraturas nos basaltos de Ribeirão Preto, SP: Aplicação à elaboração de modelo hidrogeológico conceitual. Geologia USP. Série Científica, 11(3): 43-64.

IBGE - INSTITUTO BRASILEIRO DE GEOGRAFIA E ESTATÍSTICA. 1979. Carta Topográfica de Ribeirão Preto, SF-23-V-C-I-1, escala 1:50.000, $2^{a}$. ed. IBGE, Diretoria de Geodésia e Cartografia, Superintendência de Cartografia.

INVERNIZZI, A.L. 2001. Caracterização hidrogeoquímica do Aquífero Botucatu, no setor médio da bacia hidrográfica Mogi-Pardo. Instituto de Geociências, Universidade de São Paulo, São Paulo, Dissertação de Mestrado, 103 p.

IPT/SP - INSTITUTO DE PESQUISAS TECNOLÓGICAS DO ESTADO DE SÃO PAULO. 2000. Diagnóstico da situação atual dos recursos hídricos e estabelecimento de diretrizes técnicas para a elaboração do Plano da Bacia Hidrográfica do Rio Pardo. Relatório $\mathrm{n}^{\circ} 40670$ (Relatório Zero) apresentado ao CBH-Pardo, 3 vol., 720 p.

MASSOLI, M. 2007. Caracterização litofaciológica das formações Piramboia e Botucatu, em subsuperficie, no município de Ribeirão Preto (SP), e sua aplicação na prospecção de águas subterrâneas. Instituto de Geociências e Ciências Exatas, UNESP, Rio Claro, Tese de Doutorado, 174 p.

MASSOLI, M.; CAETANO-CHANG, M.R. 2007. $\mathrm{O}$ contato entre as formações Botucatu e Piramboia na área de Ribeirão Preto (SP). Geociências, 26(3): 263-270.

MEZZALIRA, S; AZEVEDO, A.A.B.; TOMINAGA, L.K.; PRESSINOTTI, M.M.N.; MASSOLI, M. 1981. Léxico estratigráfico do Estado de São
Paulo. São Paulo: Instituto Geológico, 161 p. (Boletim, 5).

PAULA E SILVA, F. 2003. Geologia de subsuperficie e hidroestratigrafia do Grupo Bauru no estado de São Paulo. Instituto de Geociências e Ciências Exatas, UNESP/Rio Claro, Tese de Doutorado, $167 \mathrm{p}$.

PAULA E SILVA, F.; CHANG, H.K.; CAETANOCHANG, M.R.; SINELLI, O. 2008. Arcabouço geológico e hidrofácies do Sistema Aquífero Guarani no município de Ribeirão Preto (SP). Revista Brasileira de Geociências, 38(1): 56-67.

PRESSINOTTI, M.M.N. 1991. Caracterização geológica e aspectos genéticos dos depósitos de argilas do tipo "ball clay" de São Simão, São Paulo. Instituto de Geociências, Universidade de São Paulo, São Paulo, Dissertação de Mestrado, 141 p.

SANTORO, J.; MASSOLI, M. 1985. Mapa de contorno estrutural do topo do basalto subjacente ao Grupo Bauru no estado de São Paulo. Revista do Instituto Geológico, 6(1/2): 39-44.

SCHERER, C.M.S. 2000. Eolian dunes of the Botucatu Formation (Cretaceous) in southernmost Brazil: morfology and origin. Sedimentary Geology, 137: 63-84.

SIMONATO, M.D.; CAMPOS, J.E.; LEITÃO, A.C.F.; BRANDÃO, D.; PAULA E SILVA, F.; PAULA, V.F. 2016. Há conexão hidráulica entre os sistemas aquíferos Guarani e Bauru na "janela" de basalto, em Bauru-SP? In: ABAS, CONGRESSO BRASILEIRO DE ÁGUAS SUBTERRÂNEAS, 19, Campinas, Anais, p. 1-20.

SINELLI, O. 1971. Considerações gerais sobre a tectônica no município de Ribeirão Preto. In: SBG, CONGRESSO BRASILEIRO DE GEOLOGIA, 25, São Paulo, Anais, p. 145151.

SINELLI, O.; SOUZA, A.; DAVINO,A.; SANCHES, J.L. 1984. As intrusivas básicas e suas implicações na prospecção de água subterrânea. In: ABAS, CONGRESSO BRASILEIRO DE ÁGUAS SUBTERRÂNEAS, 3, Fortaleza, Anais, p. 442- 448. 
SOARES, P.C.; SINELLI, O.; PENALVA, F.;
WERNICK, E.; SOUZA, A.; CASTRO, P.R.M. 1973. Geologia do nordeste do Estado de São Paulo. In: SBG, CONGRESSO BRASILEIRO DE GEOLOGIA, 27, Aracaju, Anais, 1: 209-228.
ZALAN, P.; WOLFF, S.; CONCEIÇÃO, J.C.J.; ASTOLFI, M.A.M.; VIEIRA, I.S.; APPI, V.T.; ZANOTTO, O.A. 1987. Tectônica e sedimentação da bacia do Paraná. In: $S B G$, SIMPÓSIO SUL-AMERICANO DE GEOLOGIA, 3, Curitiba, Atas, 1: 441-447.

\section{Endereço do autor:}

Marcos Massoli - Rua Jordão Fávero, 420, ap. 308, Bairro Lagoinha, CEP 14095-060, Ribeirão Preto, SP, Brasil.E-mail: marcosmas1a@hotmail.com

Artigo submetido em 3 de dezembro de 2018, aceito em 20 de julho de 2019. 